\title{
O fornecimento de medicamentos sem registro na Anvisa pelo poder público por força de decisão judicial após o julgamento do Tema 500 pelo Supremo Tribunal Federal
}

\author{
Supplying medicines without Anvisa's registration by the State due to Court decision after the \\ Brazilian Supreme Court judgment of Item 500 \\ El suministro de drogas sin registro en Anvisa por el poder público en virtud de una decisión \\ judicial después de la sentencia del Tribunal Supremo de Brasil sobre el Tema 500
}

Ana Paula Ferreira dos Santos ${ }^{1}$

\begin{abstract}
Resumo
Objetivo: analisar as novas hipóteses permissivas para a dispensação de medicamentos sem registro na Agência Nacional de Vigilância Sanitária pelo poder público por meio de ação judicial após o julgamento do Tema de Repercussão Geral no 500 pelo Supremo Tribunal Federal. Método: foi utilizado o método de análise dedutivo para compreender o alcance do julgamento do Tema 500, além de pesquisa da legislação prévia existente e artigos correlatos. Resultado e discussão: duas novas hipóteses foram criadas pelo Supremo Tribunal Federal em que será permitido demandar a União Federal para fornecer medicações sem registro, quais sejam, mora na apreciação do pedido de registro do medicamento pela Anvisa e casos de drogas órfãs. Há vulneração ao princípio da segurança jurídica em virtude da falta da modulação para uniformizar a aplicação de seus efeitos nos processos judiciais em curso. Conclusão: apesar da necessidade de pronunciamento definitivo pelo STF, em virtude das decisões conflitantes, tecnicamente não havia um vazio legislativo apto a justificar a intervenção do Poder Judiciário.
\end{abstract}

Palavras-chave: Saúde Pública. Registro de medicamentos. Agência Nacional de Vigilância Sanitária. Judicialização da Saúde.

\section{Abstract}

Objective: to analyze the new permissive hypotheses for the dispensation of drugs without registration with the National Health Surveillance Agency by the government through a lawsuit after the judgment of General Repercussion No. 500 by the Supreme Court. Method: The deductive analysis method was used to understand the scope of the Item No. 500 judgment, in addition to researching existing prior legislation and related articles. Result and discussion: two new hypotheses were created by the Federal Supreme Court in which it will be allowed to sue the Federal Union to provide unregistered medications, namely, the consideration of Anvisa's application for registration of the drug and cases of orphan drugs. There is a violation of the principle of legal certainty due to the lack of modulation to standardize the application of its effects in ongoing judicial proceedings. Conclusion: despite

\footnotetext{
${ }^{1}$ Bacharel em Direito pela Faculdade de Direito de São Bernardo do Campo; Procuradora do Estado de São Paulo; integrante da Coordenadoria Judicial de Saúde Pública da Procuradoria-Geral do Estado de São Paulo (COJUSP), São Paulo, Brasil. E-mail: apfsantos@sp.gov.br
} 
the need for definitive pronouncement by the Supreme Court, due to the conflicting decisions, technically there was no legislative void to justify the intervention of the Judiciary.

Keywords: Public health. Medication registration. National Health Surveillance Agency. Health's judicialization.

\section{Resumen}

Objetivo: analizar las nuevas hipótesis permisivas para la dispensación de drogas sin registro en la Agencia Nacional de Vigilancia Sanitaria por parte del gobierno a través de una demanda después de la sentencia del Tribunal Supremo sobre el Tema de Repercusión General No. 500. Método: el método de análisis deductivo se utilizó para comprender el alcance del juicio del Tema 500, además de investigar la legislación anterior existente y los artículos relacionados. Resultado y discusión: el Tribunal Supremo Federal creó dos nuevas hipótesis en las que se le permitirá demandar a la Unión Federal para proporcionar medicamentos no registrados, a saber, la consideración de la solicitud de Anvisa para el registro del medicamento y los casos de medicamentos huérfanos. Existe una violación del principio de seguridad jurídica debido a la falta de modulación para estandarizar la aplicación de sus efectos en los procedimientos judiciales en curso. Conclusión: a pesar de la necesidad de un pronunciamiento definitivo por parte de la Corte Suprema, debido a las decisiones en conflicto, técnicamente no hubo un vacío legislativo capaz de justificar la intervención del Poder Judicial.

Palabras clave: Salud pública. Registro de medicación. Agencia Nacional de Vigilancia Sanitaria. Judicialización de la salud.

\section{Introdução}

A controvérsia relativa à obrigatoriedade de o Estado fornecer, ou não, medicamento não registrado na Agência Nacional de Vigilância Sanitária (Anvisa) ante o direito à saúde constitucionalmente garantido teve sua Repercussão Geral reconhecida desde 17 de novembro de 2011 pelo Supremo Tribunal Federal, contudo, apenas na sessão plenária realizada em 22 maio de 2019, o Tema n 500 - Dever do Estado de fornecer medicamento não registrado pela Anvisa (1) - foi julgado.

Tratou-se de um julgamento histórico, uma vez que o tema sempre foi polêmico, dada à existência de legislação proibitiva desconsiderada pelo Poder Judiciário no julgamento de demandas individuais em busca de produtos e serviços de saúde.

Todavia, sempre houve uma resistência do Poder Judiciário em negar os pedidos formulados em ações judiciais com esse conteúdo, não obstante a proibição legislativa já existente, fato que ocasionou um alargamento quase ilimitado do conteúdo do direito à saúde, presente no artigo 196 da Constituição Federal (2), de maneira que restou necessário 
dirimir a questão em âmbito nacional para acabar com quaisquer dúvidas a respeito da indispensável observância das normas técnicas de controle sanitário expedidas pela Anvisa.

Em virtude do recente julgamento do Tema de Repercussão Geral no 500 (1) pelo STF, finalmente as hipóteses para dispensação de medicamentos sem registro são taxativas e cada uma delas, em conjunto com suas respectivas consequências, serão analisadas no corpo deste trabalho.

O objetivo do presente estudo é apresentar as hipóteses permissivas para a dispensação de medicamentos sem registro na Agência Nacional de Vigilância Sanitária por ação judicial após o julgamento do Tema de Repercussão Geral nº 500 pelo Supremo Tribunal Federal.

Foi utilizado o método de análise dedutivo para compreender e interpretar o alcance do Tema de Repercussão Geral nำ500 e suas consequências práticas; foi feita uma pesquisa da legislação prévia existente sobre a proibição de fornecimento de medicamentos sem registro pelo poder público; e, por fim, uma análise bibliográfica, a partir de artigos e jurisprudência dos tribunais.

\section{As leis proibitivas de fornecimento de medicamento sem registro na Anvisa pelo Poder Público}

A despeito da necessidade de um pronunciamento em caráter definitivo pela Corte Suprema sobre o tema, por força da existência de milhares de demandas judiciais para fornecimento de medicamentos sem registro no órgão de vigilância sanitária nacional, nunca é demais enfatizar que a dispensação de fármacos nessas condições sempre foi proibida por força de lei.

No intuito de dar cumprimento aos preceitos constantes dos artigos 197 e 200, incisos I e II, ambos da Constituição Federal (2), foi editada a Lei Federal no 9.782, de 26 de janeiro de 1999 (3), criando a Anvisa, cuja finalidade institucional é promover a proteção da saúde da população, por intermédio do controle sanitário da produção e da comercialização de produtos e serviços submetidos à vigilância sanitária, inclusive dos ambientes, dos processos, dos insumos e das tecnologias a eles relacionados, bem como o controle de portos, aeroportos e de fronteiras (artigo 6을. 
Compete, portanto, exclusivamente à Anvisa a concessão de registros de medicamentos e produtos de saúde, por meio da análise de sua segurança e eficácia, além do exercício do controle sanitário de tais produtos para que possam ser comercializados em território nacional (3). Por essa razão, a nossa legislação estabelece regras proibitivas para evitar a comercialização e o consumo de produtos de saúde carentes de registro.

A Lei Federal no 6.360, de 23 de setembro de 1976 (4), é bastante clara ao estabelecer que os medicamentos, as drogas e os insumos farmacêuticos (artigo $1^{\circ}$ ), inclusive os importados, não podem ser expostos à venda ou entregues a consumo, antes de registrados no Ministério da Saúde (artigo 12), sob pena de se configurar infração de natureza sanitária (artigo 66).

A introdução trazida pela Lei Federal no 12.401, de 28 de abril de 2011 (5), cujo conteúdo altera a Lei Federal n 8.080, de 19 de setembro de 1990, assim expressa:

Artigo 19-T. São vedados, em todas as esferas de gestão do SUS:

I - o pagamento, o ressarcimento ou o reembolso de medicamento, produto e procedimento clínico ou cirúrgico experimental, ou de uso não autorizado pela Agência Nacional de Vigilância Sanitária - ANVISA; II a dispensação, o pagamento, o ressarcimento ou o reembolso de medicamento e produto, nacional ou importado, sem registro na Anvisa. (grifo da autora)

Também o artigo 273, parágrafo 1ํ-B, inciso I, do Código Penal, com a redação que Ihe deu a Lei Federal no 9.677, de 02 de julho de 1998 (6), considera crime hediondo importar, vender, expor à venda, ter em depósito para vender ou, de qualquer forma, distribuir ou entregar a consumo o produto sem registro, quando exigível, no órgão de vigilância sanitária competente.

O Código de Ética Médica (7), aprovado pelo Conselho Federal de Medicina, além de determinar aos médicos que observem as práticas cientificamente reconhecidas e respeitem a legislação, também impõe determinadas vedações no exercício de suas atividades profissionais. Exemplo disso é proibição inserta em seu artigo 102:

Art. 102. Deixar de utilizar a terapêutica correta, quando seu uso estiver liberado no País.

Parágrafo único. A utilização de terapêutica experimental é permitida quando aceita pelos órgãos competentes e com o consentimento do 
paciente ou de seu representante legal, adequadamente esclarecidos da situação e das possíveis consequências. (7)

O conjunto legislativo confirma que a introdução de medicamentos sem registro, em território nacional, à revelia dos controles sanitários tecnicamente instituídos, repercute de modo negativo na execução de políticas públicas de saúde, visto que retira da Anvisa a função reguladora, além de implicar em um gasto não planejado ao Estado (9).

Nesse sentido, é o entendimento de Alves, Delduque e Santos (9) ao se posicionarem contrariamente à autorização do uso de substância experimental, que o registro é o instrumento pelo qual o Estado monitora a segurança, eficácia e qualidade terapêutica do produto:

A concessão do registro de medicamentos - e as etapas que o precedem compreende uma importante questão de saúde pública, e não apenas um requisito técnico-administrativo. Durante esse processo, os critérios de qualidade, eficácia e segurança do produto são avaliados, sopesando o binômio risco/benefício. Em outras palavras, o Estado garante e se responsabiliza pela comercialização e consumo do medicamento tomando como base as evidências científicas insertas nas pesquisas clínicas. É por meio do registro do medicamento junto à Agência Nacional de Vigilância Sanitária (ANVISA) que o Estado pode acompanhar o seu uso em larga escala, observando os seus efeitos adversos. De forma complementar, mas sempre tendo como norte a garantia do direito à saúde da população, o Estado pode cancelar o registro de medicamentos, suspendendo a sua comercialização e uso quando observado que os riscos à saúde são maiores que os benefícios. Todas essas decisões são sempre motivadas pelo paradigma científico.

Não se pode perder de vista que a eficiência desses instrumentos de controle é que será capaz de propiciar medicamentos de qualidade disponíveis para o consumo da população (9).

Delduque e Lyra (10), em artigo sobre o ato administrativo de concessão de registro de medicamentos pela Anvisa, também destacam a complexidade do processo de registro de medicamentos:

É possível identificar a complexidade que envolve a análise de documentação para registro de medicamentos apenas por observar a quantidade de assuntos envolvidos nos regulamentos, que devem ser cumpridos pelas empresas solicitantes, para que seja deferida a petição de registro de medicamentos. A análise, portanto, requer muito conhecimento técnico e tem como finalidade principal fornecer à população medicamentos com qualidade, segurança e eficácia. Comparando-se o processo de registro de 
medicamentos atual com o efetuado pelos órgãos competentes anteriores à Anvisa, em ordem cronológica a Secretaria Nacional de Vigilância Sanitária e Secretaria de Vigilância Sanitária, pode-se perceber que hoje existe uma preocupação maior com esta análise técnica, pois antes o registro era considerado apenas um ato cartorial (10).

Tais normas têm sua razão de ser: o registro do medicamento perante a Anvisa objetiva garantir a sua segurança e eficácia para o uso que se propõe, tanto do ponto de vista clínico como terapêutico.

\section{O enfrentamento da questão pelos Tribunais Superiores}

O Poder Judiciário atribuiu um caráter quase absoluto ao direito à saúde, na medida em que, segundo Kozan (8), garantiu a certeza de um resultado final favorável ao paciente na quase totalidade das ações propostas com essa finalidade. Com isso, levou a um crescimento na propositura de ações judiciais buscando produtos e serviços de saúde, fato que criou um problema nacional e com grande impacto nas contas públicas de todos os entes federativos (11).

A certeza de um provimento final favorável acarretou o aumento da judicialização também das medicações sem registro na agência reguladora, fato que pode ser entendido como mais danoso para o Poder Público comparado aos pleitos por medicamentos apenas não padronizados em protocolos clínicos do SUS, porquanto ocasiona uma desorganização no sistema regulatório de saúde, pois desloca para fora da órbita de alcance do ordenamento sanitário vigente a vigilância sobre a substância (9).

Em adição, as decisões judiciais determinavam o fornecimento de medicações carentes de registro em prazos exíguos, de cumprimento impossível pela Administração, considerado o longo e burocrático trâmite para desembaraço aduaneiro (12).

Presente a relevância nos âmbitos econômico, social, político e jurídico, o pronunciamento, em caráter definitivo pelos Tribunais Superiores, era uma medida imprescindível para regulamentar a questão de forma mais clara.

Primeiro, o Recurso Especial (RE) no 1.657.156/RJ foi afetado pelo sistema dos recursos repetitivos (Tema n 106) para enfrentar a obrigatoriedade do Poder Público de fornecer medicamentos não incorporados em atos normativos do SUS (13), ocasião em que 
restaram estabelecidos requisitos para a dispensação de fármacos nessas condições, dentre eles, a existência de registro na Anvisa.

Ainda que permitido o fornecimento de medicamento não incluído em programa de dispensação do SUS e cumpridos os requisitos, o registro na Anvisa é condição essencial para o deferimento de medidas administrativas e judiciais.

Observa-se uma evolução da jurisprudência sobre o tema, iniciada com o julgamento do Recurso Especial (RE) ㄲo 1.657.156/RJ (13), que também motivou a alteração no conteúdo original dos Enunciados ํo 06 e 50, durante a III Jornada de Direito da Saúde do Conselho Nacional de Justiça, realizada em 18 de março de 2019 (15), os quais possuem uma função auxiliar na tomada de decisões pelo magistrado (14). Os enunciados atualmente apresentam a seguinte redação:

\section{Enunciado no 06}

A determinação judicial de fornecimento de fármacos deve evitar os medicamentos ainda não registrados na Anvisa ou em fase experimental, ressalvadas as exceções expressamente previstas em lei (STJ - Recurso Especial Resp. oㅜ 1.657.156, Relatoria do Ministro Benedito Gonçalves - 1a Seção Cível - julgamento repetitivo dia 25.04.2018 - Tema 106). (Redação dada pela III Jornada de Direito da Saúde - 18.03.2019)

\section{Enunciado nํ 50}

Não devem ser deferidas medidas judiciais de acesso a medicamentos e materiais não registrados na Agência Nacional de Vigilância Sanitária - ANVISA ou deferidas medidas judiciais que assegurem acessos a produtos ou procedimentos experimentais (Tema 106 STJ STJ - Recurso Especial Resp. № 1.657.156, Relatoria do Ministro Benedito Gonçalves - 1a Seção Cível - julgamento repetitivo dia 25.04.2018 e RE 566471/RN, RE 657718/MG do STF). (Redação dada pela III Jornada de Direito da Saúde - 18.03.2019)

Mais recentemente, em sessão plenária, realizada em 22 de maio de 2019, o STF julgou o Tema de Repercussão Geral n 500 (1), que trata especificamente da questão, quando firmou-se a seguinte tese:

1. O Estado não pode ser obrigado a fornecer medicamentos experimentais.

2. A ausência de registro na ANVISA impede, como regra geral, o fornecimento de medicamento por decisão judicial. 
3. É possível, excepcionalmente, a concessão judicial de medicamento sem registro sanitário, em caso de mora irrazoável da ANVISA em apreciar o pedido (prazo superior ao previsto na Lei $\mathrm{n}^{\circ}$ 13.411/2016), quando preenchidos três requisitos:

(i) a existência de pedido de registro do medicamento no Brasil (salvo no caso de medicamentos órfãos para doenças raras e ultrarraras); (ii) a existência de registro do medicamento em renomadas agências de regulação no exterior; e

(iii) a inexistência de substituto terapêutico com registro no Brasil.

4. As ações que demandem fornecimento de medicamentos sem registro na ANVISA deverão necessariamente ser propostas em face da União" (1).

O STF trouxe uma regulamentação mais clara acerca da impossibilidade de dispensação de medicamentos sem registro como regra, porém estabeleceu duas novas exceções: (i) mora irrazoável da Anvisa em apreciar o pedido de registro; e (ii) pedidos de "drogas órfãs, ou seja, o único medicamento existente no mundo, sem registro no órgão de vigilância nacional, porém com registro em agências internacionais, atendidos cumulativamente todos os demais requisitos".

Em relação à primeira hipótese, adota-se o prazo de um ano trazido pela Lei Federal no 13.411 , de 28 de dezembro de 2016 (16):

Art. $2^{\circ}$ A Lei $n^{\circ}$ 6.360, de 23 de setembro de 1976, passa a vigorar acrescida do seguinte art. 17-A:

"Art. 17-A. Os prazos estabelecidos para a decisão final nos processos de registro e de alteração pós-registro de medicamento levarão em conta os seguintes critérios:

$\S 2^{\circ}$ Os prazos máximos para a decisão final nos processos de registro e de alteração pós-registro de medicamento serão, respectivamente: I - para a categoria prioritária, de cento e vinte dias e de sessenta dias, contados a partir da data do respectivo protocolo de priorização; II para a categoria ordinária, de trezentos e sessenta e cinco dias e de cento e oitenta dias, contados a partir da data do respectivo protocolo de registro ou de alteração pós-registro.

Passado um ano após o protocolo do pedido de registro da medicação junto à Anvisa, existente o registro do medicamento em renomadas agências de regulação no exterior, como é o caso, por exemplo, da Food and Drug Administration (FDA) e European Medicines Agency (EMA), e ausente uma alternativa terapêutica registrada no país, será possível 
pleitear judicialmente a substância. Contudo, um problema que pode se avizinhar com essa exigência é como obter essa informação de caráter tão técnico.

Entende-se que tal conhecimento está inserido também nas atribuições do profissional prescritor, o qual possui o dever de conhecer o tratamento prescrito. Os artigos $3^{\circ}$ e e $4^{\circ}$, todos do Código de Ética Médica (7), estabelecem que "é vedado ao médico deixar de assumir responsabilidade sobre qualquer ato profissional que tenha praticado, indicado ou participado."

De qualquer forma, a Anvisa disponibiliza a consulta sobre a existência de registro de medicamentos em seu sítio eletrônico, seja a partir da indicação do seu princípio ativo, seja a partir de seu nome comercial (17).

Outro aspecto que merece atenção diz respeito à existência de registro do medicamento em renomadas agências de regulação no exterior, a exemplo da FDA, porquanto tal agência tende a ser menos rigorosa que a Anvisa na aprovação de novas indicações (18).

Em artigo elaborado por profissionais integrantes da Secretaria de Saúde do Estado de São Paulo a respeito da judicialização de medicamentos imunoterápicos sem registro na Anvisa (18), os autores destacam que há um menor rigor da FDA e EMA na aprovação do registro de novas drogas:

A comparação das bulas mostrou que, de forma geral, a FDA tende a ser menos rigorosa na aprovação de novas indicações para o medicamento, com muitas aprovações fast track, ou seja, aprovação acelerada baseada em taxa da resposta tumoral e duração da resposta, sendo necessário, para a continuidade do registro, comprovação de eficácia em estudos confirmatórios (18).

E também:

Um estudo que avaliou 68 indicações de medicamentos oncológicos aprovados pela EMA, entre 2009 e 2013, mostrou que 39 (57\%) entraram no mercado europeu sem que tenham comprovado melhora na sobrevivência ou qualidade de vida dos pacientes; nos casos em que havia comprovação estatística de melhoria, a maioria não representava benefício clínico (21). Cenário muito semelhante já havia sido demonstrado nos Estados Unidos, considerando as aprovações da $\operatorname{FDA}(22,23)$. Existe a preocupação de que a aprovação baseada em escassa evidência como última alternativa para os 
pacientes possa promover expectativas irreais, tanto para os prescritores quanto pacientes e familiares (19).

Quanto à segunda hipótese, em que o STF entendeu possível a ação judicial para o fornecimento de fármacos carentes de registro no país para o tratamento de doenças raras, ultrarraras ou degenerativas, não é necessário o prévio pedido de registro no país junto à Anvisa das chamadas drogas órfãs para possibilitar a propositura da ação judicial. Contudo, a comprovação do registro do medicamento em renomadas agências de regulação no exterior e ausência, por óbvio, de alternativa terapêutica registrada no país, seguem necessárias.

Considera-se doença rara aquela que afeta até 65 pessoas em cada 100.000 indivíduos, ou seja, 1,3 pessoas para cada 2.000 indivíduos, segundo o artigo $3^{\circ}$ da Portaria no 199 do Ministério da Saúde (19).

Os medicamentos órfãos, segundo matéria publicada pelo Senado Federal (20), recebem esse nome devido ao pouco interesse da indústria farmacêutica, porque, em condições normais de mercado, não é vantajoso desenvolver remédios destinados a um pequeno número de doentes. Por esse motivo, tais fármacos possuem quase sempre um custo elevadíssimo.

Ressalta-se que a autorização para fornecimento de medicamentos órfãos sem registro na Anvisa não é definitiva, ao passo que, inevitavelmente, sofrerá influência quando do julgamento do Tema no 06 de Repercussão Geral - Dever do Estado de fornecer medicamento de alto custo a portador de doença grave que não possui condições financeiras para comprá-lo (21). Resta saber se, em caso de reconhecimento da ausência do dever do Estado de fornecer medicamento de alto custo, a droga órfã figurará como exceção à regra ou a possibilidade de fornecimento será revista.

Também, em sessão de 25 de julho de 2018, foi aprovado no Senado Federal o Projeto de Lei da Câmara ํำ56, de 16 de setembro 2016, pendente de sanção, cujo conteúdo institui a Política Nacional para Doenças Raras no SUS (22). A novidade legislativa diz respeito à análise prioritária para a concessão de registro sanitário na Anvisa do medicamento órfão destinado ao diagnóstico, prevenção e tratamento de doença rara (artigo 25).

Os fabricantes de medicamentos órfãos submeterão um pedido de designação de droga órfã com, no mínimo, seis meses de antecedência da data de submissão do dossiê de 
registro perante a Anvisa (artigo $25, \S 2^{\circ}$ ), a qual deve se manifestar sobre o reconhecimento da designação como medicamento órfão e sobre a concessão do registro em até 45 dias contados das respectivas submissões (artigo 26), e a inobservância de tal prazo implicará na concessão automática do registro sanitário (artigo 27).

Outra questão de ordem processual trazida pelo STF diz respeito à legitimidade passiva, visto que restou estabelecido que as ações que demandem fornecimento de medicamentos sem registro na Anvisa deverão ser necessariamente propostas em face da União, tanto nos casos de mora irrazoada dos pedidos de registro, como de fornecimento de medicamento órfão, atraindo a competência absoluta para conhecimento de tais ações para a Justiça Federal, de acordo com o artigo 109, inciso I, da Constituição Federal (2).

O acerto da decisão, no tocante à necessidade de ajuizamento da ação com esse fim em face apenas da União, é evidente, visto que compete exclusivamente à Anvisa conceder registros de medicamentos e produtos de saúde.

No que se refere à análise efetiva da mora administrativa na apreciação do pedido de registro de medicamento pelo prazo superior a um ano, tal condição poderá ser aferida apenas pela União por ser a Anvisa um órgão integrante da estrutura da Administração Pública Federal.

Tal previsão veio dotar de maior concretude o teor do Enunciado ํㅡㄴ 78, do CNJ (15), o qual já recomendava o processamento de tais ações perante a Justiça Federal, nesses termos:

\footnotetext{
Enunciado nำ 78

Compete à Justiça Federal jugar as demandas em que são postuladas novas tecnologias de alta complexidade ainda não incorporadas ao Sistema Único de Saúde - SUS (15).
}

Frise-se que nosso sistema normativo tutela a intervenção da União nas ações judiciais cuja decisão possa ter reflexos, ainda que indiretos, de natureza econômica, casos em que será considerada parte na ação e haverá o deslocamento de competência para a Justiça Federal, consoante preceitua o artigo 5º, da Lei Federal ํo 9.469, 10 de julho de 1997 (23). 


\section{Críticas ao novo posicionamento do Supremo Tribunal Federal}

O que de fato ocorreu foi a criação pelo STF de um novo regramento excepcional para a dispensação de medicamentos carentes de registro na Anvisa pelo Poder Público e não a confirmação da proibição já presente em nosso ordenamento jurídico.

Ainda que as hipóteses que possibilitam a dispensação de medicamentos sem registro na Anvisa em virtude de decisão judicial sejam excepcionais, uma vez que decorrentes de alguma mora administrativa, seja na concessão do registro, seja na implementação de tratamentos para doenças raras, tal intervenção judicial deve ser vista com cautela, sob pena de desprestigio da atuação do órgão de vigilância sanitária.

Sob outro aspecto, ao contrário do STJ que, ao julgar o Tema № 106 (13), modulou os efeitos da decisão para tornar aplicável as novas balizas apenas para ações propostas após 04 de maio de 2018, data da publicação do acórdão, não houve qualquer menção do STF atinente à modulação dos efeitos da decisão do Tema № 500 (1).

Com o advento da Lei Federal no 9.868, de 10 de novembro de 1999 (24), em especial por força do artigo 27 , houve a positivação do instituto da modulação dos efeitos das decisões judiciais pelos Tribunais Superiores (25).

Também o Código de Processo Civil (CPC) expressa (26), em seus artigos 926, caput, e 927, parágrafo $3^{\circ}$, respectivamente:

Art. 926. Os tribunais devem uniformizar sua jurisprudência e mantêla estável, íntegra e coerente.

Art. 927. Os juízes e os tribunais observarão:

(...)

$\S 3^{\circ}$ Na hipótese de alteração de jurisprudência dominante do Supremo Tribunal Federal e dos tribunais superiores ou daquela oriunda de julgamento de casos repetitivos, pode haver modulação dos efeitos da alteração no interesse social e no da segurança jurídica.

Tais dispositivos legais objetivam assegurar o respeito ao princípio da segurança jurídica, visto que a existência de diversas relações jurídicas formadas a partir de entendimentos equivocados da legislação vigente pedia um enfrentamento de determinadas questões em caráter definitivo pelo Poder Judiciário.

A celeuma é de ordem processual no presente caso, pois os pleitos judicializados para a dispensação de medicamentos sem registro no órgão de vigilância sanitária serão 
propostos apenas em face da União, situação que atrai a competência para processamento de tais ações necessariamente para a Justiça Federal.

Partindo-se da premissa de que o regramento de ordem processual possui aplicação imediata aos processos em curso, indaga-se: o que fazer com as ações judiciais em trâmite? Todas as ações propostas para esse fim serão imediatamente remetidas para a Justiça Federal? Haverá o reconhecimento instantâneo da ilegitimidade passiva dos Municípios e Estados-membros incluídos no polo passivo? Cessa o fornecimento nas ações com decisão favorável antecipatória aos pacientes? A alteração alcançaria a fase de cumprimento de sentença?

A solução para o impasse parece ser a aplicação do entendimento adotado pela Corte Suprema no Conflito de Competência no 7.204 (27), instaurado em virtude da dúvida a respeito do termo inicial do marco temporal da competência da Justiça do Trabalho, após o advento da Emenda Constitucional № 45 (28), para apreciar e julgar ação de indenização decorrente de acidente de trabalho, ajuizada contra o empregador.

Na ocasião restou estabelecido:

Nada obstante, como imperativo de política judiciária - haja vista o significativo número de ações que já tramitaram e ainda tramitam nas instâncias ordinárias, bem como o relevante interesse social em causa -, o Plenário decidiu, por maioria, que o marco temporal da competência da Justiça trabalhista é o advento da EC 45/2004. Emenda que explicitou a competência da Justiça Laboral na matéria em apreço. 4. A nova orientação alcança os processos em trâmite pela Justiça comum estadual, desde que pendentes de julgamento de mérito. É dizer: as ações que tramitam perante a Justiça comum dos Estados, com sentença de mérito anterior à promulgação da EC 45/2004, lá continuam até o trânsito em julgado e correspondente execução. Quanto àquelas cujo mérito ainda não foi apreciado, hão de ser remetidas à Justiça do Trabalho, no estado em que se encontram, com total aproveitamento dos atos praticados até então. A medida se impõe, em razão das características que distinguem a Justiça comum estadual e a Justiça do Trabalho, cujos sistemas recursais, órgãos e instâncias não guardam exata correlação (27).

Dada a aplicação imediata do novo entendimento a partir da fixação da tese do Tema № 500 (1), as demandas ajuizadas ficariam a cargo da Justiça Federal, exceto quando os processos, já em tramitação na Justiça comum, contassem com sentença de mérito proferida, lá permanecendo até o trânsito em julgado e correspondente execução. 
A solução parece a mais apropriada, em especial porque condiz com o teor do artigo 14 do CPC (22), que expressa que a norma processual "será aplicável imediatamente aos processos em curso, respeitados os atos processuais praticados e as situações jurídicas consolidadas sob a vigência da norma revogada".

\section{Conclusão}

Este estudo procurou esclarecer que a proibição de fornecimento de medicamentos sem registro na Anvisa pelo Poder Público, nas esferas administrativa e judicial, sempre foi a opção do legislador pátrio por razões de ordem sanitária. Todavia, o Poder Judiciário, ao julgar as demandas com esse conteúdo, quase sempre ignorou a produção legislativa existente, fato que gerou uma infinidade de decisões judiciais em todos os sentidos possíveis, até demandar o pronunciamento em caráter vinculante do Supremo Tribunal Federal, realizado recentemente.

Não se discute a necessidade de regulamentar a questão de forma mais clara no âmbito dos Tribunais, especialmente pela existência de decisões conflitantes, contudo, nesse caso específico, não havia um vazio normativo apto a justificar a intervenção do Poder Judiciário, o qual, inclusive, foi além e criou hipóteses permissivas.

Em realidade, a dúvida a respeito da possibilidade ou não de dispensar medicamento carente de registro no órgão de vigilância sanitária nasceu no próprio Poder Judiciário, uma vez que tal órgão sempre conferiu caráter quase absoluto ao direito à saúde, constitucionalmente previsto.

Houve, portanto, a criação de exceções à legislação proibitiva existente. No que tange à primeira, mora irrazoada na apreciação do pedido de registro pela Anvisa, entende-se pertinente a hipótese, pois é dotada de caráter objetivo.

Já em relação aos medicamentos destinados ao tratamento de doenças raras, a despeito da nobre intenção, deve-se ter cautela na aplicação, visto que são substâncias de custo elevadíssimo e sempre deverá ser comprovada a ausência de alternativa de tratamento no país. Ademais, tais casos poderão sofrer influência do julgamento do Tema no 6 de Repercussão Geral e da aprovação do Projeto de Lei da Câmara ํo 56, de 2016, que trata da Política Nacional para Doenças Raras no SUS. 
Por fim, no que se refere à propositura em face da União dos pleitos judicializados para dispensação de medicamentos sem registro no órgão de vigilância sanitária e consequente atração da competência para a Justiça Federal, defende-se como marco temporal, para a permanência de tais ações na Justiça comum, a sentença de mérito, em respeito ao princípio da segurança jurídica.

\section{Referências}

1. Brasil. Supremo Tribunal Federal. Recurso Extraordinário no 657.718/MG. Recorrente: Alcirene de Oliveira. Recorrido: Estado de Minas Gerais. Relator: Ministro Marco Aurelio. Brasília. DJ: 22/05/2019. Disponível em: https://portal.stf.jus.br/processos/detalhe.asp? incidente $=4143144$ [Acesso em 31.jul.2019].

2. Brasil. Constituição da República Federativa do Brasil, 8 de outubro de 1988. Brasília: Senado Federal, 2008.

3. Brasil. Lei Federal no 9.782, de 26 de janeiro de 1999. Define o Sistema Nacional de Vigilância Sanitária, cria a Agência Nacional de Vigilância Sanitária, e dá outras providências. Brasília, 27 jan 1999. Disponível em: http://www.planalto.gov.br/ccivil_03/LEIS/L9782.htm [Acesso em 31.jul.2019].

4. Brasil. Lei Federal nํ 6.360, de 23 de setembro de 1976. Dispõe sobre a Vigilância Sanitária a que ficam sujeitos os Medicamentos, as Drogas, os Insumos Farmacêuticos e Correlatos, Cosméticos, Saneantes e Outros Produtos, e dá outras Providências.

Brasília. Disponível em: http://www.planalto.gov.br/ccivil_03/LEIS/L6360.htm [Acesso em 31.jul.2019].

5. Brasil. Lei Federal $n^{\circ}$ 12.401, de 28, de abril de 2011. Altera a Lei $n^{\circ} 8.080$, de 19 de setembro de 1990, para dispor sobre a assistência terapêutica e a incorporação de tecnologia em saúde no âmbito do Sistema Único de Saúde - SUS. Brasília. Disponível em: http://www.planalto.gov.br/ccivil_03/_ato2011-2014/2011/lei/l12401.htm [Acesso em 31.jul.2019].

6. Brasil. Lei Federal n 9.677, de 02 de julho de 1998. Altera dispositivos do Capítulo III do Título VIII do Código Penal, incluindo na classificação dos delitos considerados hediondos crimes contra a saúde pública, e dá outras providências. Brasília. Disponível em: http://www.planalto.gov.br/ccivil_03/LEIS/L9677.htm [Acesso em 31.jul.2019].

7. Brasil. Conselho Federal de Medicina. Resolução № 1931, de 24 de setembro de 2009. Aprova o Código de Ética Médica. Diário Oficial da União da República Federativa do Brasil. (24 set. 2009); Seção I, p. 90. 
8. Kozan, Juliana Ferreira. (2019). Por que paciente com câncer vão à Justiça? Um estudo sobre ações judiciais movidas contra o Sistema Único de Saúde (SUS) e contra os planos de saúde na Cidade de São Paulo. São Paulo. p: 73. Disponível em: http://scholar.google.com.br/ scholar_url?url=http:/www.teses.usp.br/teses/disponiveis/5/5137/tde-03102019-114604/publico/ JulianaFerreiraKozan. pdf\&hl=ptBR\&sa $=X \& d=8045966167507376753 \&$ scisig=AAGBfm0SD L2RwoWQ_SUFodoCDbIMyDe 9ZA\&nossl=1\&oi=scholaralrt\&hist=63byc1AAAAAJ:171925 71757549465270:AAGBfm1WcXXoVTMM7EbsHPBUyxeR0FmbDA [Acesso em 07.out.2019].

9. Alves SM, Delduque MC, Santos, AO (2016). Lei no 13.269/2016: a comoção da sociedade vence o método científico! Cad. Saúde Pública. Rio de Janeiro, 2016. Disponível em: http://www.scielo.br/scielo.php?script=sci_arttext\&pid=S0102-311X2016000600301 [Acesso em 06.out.2019].

10. Lyra D, \& Delduque M (2010). O ato administrativo de concessão de registro de medicamentos na Agência Nacional de Vigilância Sanitária. Revista De Direito Sanitário, 10(3), 11-26. https://doi.org/10.11606/issn.2316-9044.v10i3p11-26.

11. Tribunal de Contas da União. Aumentam os gastos públicos com judicialização da saúde. Brasília, 2017. Disponível em: https://portal.tcu.gov.br/imprensa/noticias/aumentamosgastos-publicos-com-judicializacao-da-saude.htm [Acesso em 01.11.2019].

12. Brasil. Ministério da Economia, Indústria, Comércio Exterior e Serviços. Portaria SECEX $\mathrm{n}^{\circ}$ 23, de 14 de julho de 2011 Dispõe sobre operações de comércio exterior. Diário Oficial da União da República Federativa do Brasil. (19 jul 2011); Seção 1, p. 65-92.

13. Brasil. Superior Tribunal de Justiça. Recurso Especial oㅜ 1.657.156/RJ. Recorrente: Estado do Rio de Janeiro. Recorrida: Fatima Theresa Esteves dos Santos de Oliveira. Relator: Ministro Benedito Gonçalves. Brasília. DJ: 25/04/2018. Disponível em : https://ww2.stj.jus.br/processo/revista/documento/mediado/?componente=ITA\&sequencial= 1641175\&num_registro=201700256297\&data $=20180504 \&$ formato=PDF [Acesso em 31.jul.2019].

14. Conselho Nacional de Justiça. III Jornada de Direito da Saúde aprova 35 novos enunciados. Brasília, 2019. Disponível em: https://www.cnj.jus.br/iii-jornada-de-direitodasaude-aprova-35-novos-enunciados/ [Acesso em 07.10.2019].

15. III Jornada de Direito da Saúde do Conselho Nacional de Justiça. 18 jun 2019, São Paulo. Disponível em: http://cnj.jus.br/eventos-campanhas/evento/777-iii-jornada-da-saude [Acesso em 31.jul.2019].

16. Brasil. Lei Federal o 13.411, de 28 de dezembro de 2016. Altera a Lei oㅡ 6.360, de 23 de setembro de 1976, que dispõe sobre a vigilância sanitária a que ficam sujeitos os medicamentos, as drogas, os insumos farmacêuticos e correlatos, cosméticos, saneantes e outros produtos, e dá outras providências, e a Lei no 9.782, de 26 de janeiro de 1999, que define o Sistema Nacional de Vigilância Sanitária, cria a Agência Nacional de Vigilância Sanitária, e dá outras providências, para dar transparência e previsibilidade ao processo de 
concessão e renovação de registro de medicamento e de alteração pós-registro. Brasília. Disponível em: http://www.planalto.gov.br/ccivil_03/_Ato20152018/2016/Lei/L13411.htm [Acesso em 31.jul.2019].

17. Agência Nacional de Vigilância Sanitária. Consulta a Medicamentos e Hemoderivados. Brasília, 2019. Disponível em: http://portal.anvisa.gov.br/medicamentos/consultas [Acesso em 31.jul.2019].

18. Oliveira DB, Silva RAM, Paula EA, Cassamassimo RP, Siqueira PSF, Melo DO. A judicialização de medicamentos imunoterápicos sem registro na Anvisa: o caso do Estado de São Paulo. Cadernos Ibero-Americanos de Direito Sanitário. Brasília, jul/set.2019. p: $27: 47$.

19. Brasil. Ministério da Saúde. Portaria no 199, de 30 de janeiro de 2014. Institui a Política Nacional de Atenção Integral às Pessoas com Doenças Raras, aprova as Diretrizes para Atenção Integral às Pessoas com Doenças Raras no âmbito do Sistema Único de Saúde (SUS) e institui incentivos financeiros de custeio. Brasília. Disponível em: http://bvsms.saude.gov.br/bvs/saudelegis/gm/2014/prt0199_30_01_2014.html [Acesso em 31.jul.2019].

20. Senado Federal. País pode contar com nova Política Nacional para Doenças Raras no SUS. Brasília, 2018. Disponível em: https://www12.senado.leg.br/noticias/materias/2018/10/24/ pais-pode-contar-com-novapolitica-nacional-para-doencas-raras-no-sus [Acesso em 31.jul.2019].

21. Brasil. Supremo Tribunal Federal. Recurso Extraordinário no 566.471/RN. Recorrente: Estado do Rio Grande do Norte. Recorrida: Carmelita Anunciada de Souza entre outros. Relator: Ministro Marco Aurelio. Brasília. DJ: 07/12/2007. Disponível em: http://www.stf.jus.br/portal/jurisprudencia/listarJurisprudencia.asp?s1=\%28RE\%24\%2ESCL A\%2E+E+566471\%2ENUME\%2E\%29+OU+\%28RE\%2EPRCR\%2E+ADJ2+566471\%2EPR CR\%2E\%29\&base=baseRepercussao\&url=http://tinyurl.com/awtjc5x [Acesso em 31.jul.2019].

22. Brasil. Projeto de Lei da Câmara ํㅡ 56, de 16 de setembro de 2016. Institui a Política Nacional para Doenças Raras no Sistema Único de Saúde - SUS. Autoria: Deputado Marçal Filho. Brasília. Disponível em: https://www25.senado.leg.br/web/atividade/materias//materia/126956 [Acesso em 31.jul.2019].

23. Brasil. Lei Federal $n^{\circ} 9.469$, de 10 de julho de 1997. Regulamenta o disposto no inciso VI do art. 4 da Lei Complementar no 73, de 10 de fevereiro de 1993; dispõe sobre a intervenção da União nas causas em que figurarem, como autores ou réus, entes da administração indireta; regula os pagamentos devidos pela Fazenda Pública em virtude de sentença judiciária; revoga a Lei no 8.197, de 27 de junho de 1991, e a Lei ํㅡ 9.081, de 19 de julho de 1995, e dá outras providências. Brasília. Disponível em: http://www.planalto.gov.br/ccivil_03/leis/L9469.htm [Acesso em 31.jul.2019]. 
24. Brasil. Lei Federal o 9.868, de 10 de novembro de 1999. Dispõe sobre o processo e julgamento da ação direta de inconstitucionalidade e da ação declaratória de constitucionalidade perante o Supremo Tribunal Federal. Brasília. Disponível em: http://www.planalto.gov.br/ccivil_03/LEIS/L9868.htm [Acesso em 31.jul.2019].

25. Barreto Junior, EC. A (Im)possibilidade de modulação dos efeitos da decisão que declara constitucional ato normativo impugnado em sede de Controle Abstrato de Constitucionalidade. Revista Jurídica da Procuradoria-Geral do Distrito Federal. Brasília, jan/jun.2016. p. 11:38.

26. Brasil. Lei Federal oㅜ 13.105, de 16 de março de 2015. Código de Processo Civil. Brasília. Disponível em: http://www.planalto.gov.br/ccivil_03/_ato2015-2018/2015/lei/13105.htm [Acesso em 31.jul.2019].

27. Brasil. Supremo Tribunal Federal. Conflito de Competência no 7.204. Suscitante: Tribunal Superior do Trabalho. Suscitado: Tribunal de Alçada do Estado de Minas Gerais. Relator: Ministro Ayres Britto. Brasília. DJ 29.06.2005. Disponível em: http://portal.stf.jus.br/processos/detalhe.asp?incidente=2283308 [Acesso em 31.jul.2019].

28. Brasil. Emenda Constitucional ํㅜ 45, de 30 de dezembro de 2004. Altera dispositivos dos arts. 5o, 36, 52, 92, 93, 95, 98, 99, 102, 103, 104, 105, 107, 109, 111, 112, 114, 115, 125, 126, 127, 128, 129, 134 e 168 da Constituição Federal, e acrescenta os arts. 103-A, 103B, 111-A e 130-A, e dá outras providências. Brasília. Disponível em: http://www.planalto.gov.br/ccivil_03/constituicao/emendas/emc/emc45.htm [Acesso em 31.jul.2019].

Santos APF. O fornecimento de medicamentos sem registro na Anvisa pelo poder público por força de decisão judicial após o julgamento do Tema 500 pelo Supremo Tribunal Federal. Cadernos Ibero-Americanos de Direito Sanitário. 2019 out./dez.; 8(4): 27-44.

http://dx.doi.org/10.17566/ciads.v8i4.564 